\title{
Träume wagen
}

_ Was jetzt kommt, nennt man wohl Schleichwerbung: Ich bin ein Fan des Ergotherapiekongresses. Einmal im Jahr verpasst er mir meine Portion Enthusiasmus. Natürlich brenne ich ohnehin schon für die Ergotherapie, aber ab und an tut es doch gut, einen Motivationsschubser von außen zu bekommen.

_ Besonders der Eröffnungsvortrag von Helene Polatajko hat es mir dieses Jahr angetan. Sie hat ihre Zuhörer ermutigt, einfach mal alle Bedenken beiseitezuschieben und draufloszuträumen. Ihrer Meinung nach sollten wir Ergotherapeuten viel mehr „leader“, also Macher und Anführer, sein. Sie hat uns entführt in eine Welt in Kanada und den USA, in der sich Promis einen Life Coach gönnen und in der sich reiche Mütter im Countryclub damit brüsten, $z u$ welch toller Ergotherapeutin ihr sowieso schon tolles Kind geht, um noch tollere Startbedingungen in eine wahnsinnig tolle Zukunft zu haben. So hab ich das noch nie gesehen. Wieso eigentlich immer nur kleine Brötchen backen?

_ Den Kongress mag ich aber nicht nur der Träume wegen. Auch auf dem Boden der ergotherapeutischen Tatsachen tut sich einiges. Und wie oft hat man schon die Gelegenheit, sich so umfassend über den aktuellen Stand der Dinge zu informieren? Für mich ist das eine Art Campus: Ich suche mir die Vorlesungen aus, die mich interessieren, belege vielleicht einen Workshop und treffe mich in den Pausen mit meinen Kommilitonen - es gibt ja so viel zu bereden.

_ Wer nachträglich ein wenig Kongress-Atmosphäre schnuppern möchte, dem empfehle ich unser persönliches Fotoalbum auf Seite 40.

_ Bei Redaktionsschluss lag der Anpfiff zur Fußball-Europameisterschaft übrigens noch in der Zukunft. Ich hoffe, mein schwarz-rot-goldener Traum ist noch nicht ausgeträumt, wenn das Heft bei Ihnen im Briefkasten liegt. Fußballfan bin ich nämlich auch.

Herzlichst Ihre

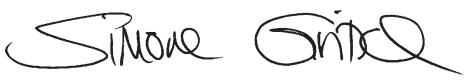

ZU GEWINNEN

Kursplatz

1 Kurs „Stressbewältigung durch Achtsamkeit"

Seite 45

Bücher

$3 x$ „Ich bin besonders“ Seite 17

2x „Das Castillo

Morales-Konzept“

Und außerdem...

1 Vanille-Wellness-Set

Seite 20

10 Panini Fanpakete

Seite 33

3 Erste-Hilfe-Taschen

Seite 36

Im ergopraxis.Refresher

2-mal „Ergotherapie bei Kindern mit Wahrnehmungsstörungen“" 